\title{
PERANCANGAN DAN REALISASI BOX ALAT UKUR PANJANG BADAN BALITA ELEKTRONIK BERBASIS PERSONAL COMPUTER (PC)
}

\section{DESIGN AND IMPLEMENTATION OF A PC-BASED ELECTRONIC TODDLER'S BODY LENGTH METER}

\author{
Willy Aulia A. Kustiana1 ${ }^{1}$ H. H. Rachmat ${ }^{1}$ \\ ${ }^{1}$ Laboratorium Elektronika, Teknik Elektro, Institut Teknologi Nasional Bandung \\ 1willyauliaakbar@gmail.com
}

\begin{abstract}
Abstrak
Dalam penelitian ini dilakukan perancangan dan realisasi box alat ukur panjang badan balita elektronik berbasis Personal Computer (PC). Alat ukur panjang badan ini dirancang dengan menggunakan transduser ultrasonik untuk mempermudah proses evaluasi perkembangan gizi balita, terutama dalam hal pengukuran panjang badan balita yang merupakan salah satu aspek parameter kesehatan gizi balita. Untuk mengetahui kualitas sistem ini dilakukan pula evaluasi nilai linieritas, kepresisian, dan akurasi dari hasil pengukur panjang badan elektronik. Sistem elektronik ini diintegrasikan dalam suatu box bayi dengan material kayu berdimensi 120x50x15 $\mathrm{cm}^{3}$, sehingga bayi dapat diukur dalam kondisi posisi telentang. Hasil output dari transduser diproses oleh sistem Arduino untuk memperoleh nilai tinggi badan balita. Data dari Arduino selanjutnya ditampilkan pada layar LCD dan dihubungkan ke PC melalui port USB. Hasil pengujian sistem menunjukkan bahwa sistem telah dapat melakukan pengukuran panjang badan dengan linieritas lebih dari 0,9 , kepresisian $0 \mathrm{~cm}$ dan keakuratan $0 \%$.
\end{abstract}

Kata kunci : box kayu, gizi balita, panjang badan, personal computer, transduser ultrasonik

\begin{abstract}
In this study, we designed and implemented an electronic device of personal computer (PC) based toddler's body length meter system. The aim of this system is to evaluate a toddler's nutrient condition relative to the body length. An ultrasonic transducer module was embedded to a wood box to measure a total time of flight of ultrasonic signal during the body length object measurement. The box had a dimension of $120 \mathrm{~cm}$ (the length) x $50 \mathrm{~cm}$ (the width) $\times 15 \mathrm{~cm}$ (the height) in order to measure the object in supine position. The time of flight was subsequently processed in Arduino Uno module to calculate the toddler's height. The height value was displayed on an LCD display and transferred to the PC via a USB port for recording and evaluating procedure. To know the system performance, we evaluated some measurement factors of the system including linearity, precision and accuracy. The results showed that the system had linearity more than 0.9 , precision of $0 \mathrm{~cm}$ and accuracy of $0 \%$.
\end{abstract}

Keywords: body length, personal computer, toddler's nutrient, ultrasonic transducer, wood box

\section{PENDAHULUAN}

Kesehatan balita merupakan faktor penting yang menjamin kelangsungan hidup generasi berikutnya [3]. Salah satu program yang dilaksanakan pemerintah untuk meningkatkan kesehatan balita adalah melalui evaluasi tingkat gizi balita secara rutin di Puskesmas dan Posyandu. Evaluasi kualitas gizi balita yang dilakukan yaitu melalui pengukuran massa tubuh (berat badan) dan 
panjang badan (tinggi badan). Dalam prakteknya pemantauan kualitas gizi balita masih banyak menggunakan metode pengukuran massa tubuh saja, sedangkan untuk metode pengukuran panjang badan masih sangat jarang digunakan. Pemantauan kesehatan gizi balita memang tidak cukup hanya dilihat melalui berat badan saja, akan tetapi jauh lebih baik bila diimbangi dengan panjang badan. Dengan menggunakan metode keduanya akan terlihat hasil penilaian gizi yang lebih akurat.

Prosedur pengukuran tinggi badan balita, saat ini di beberapa Posyandu masih dilakukan secara manual yaitu dengan skala meteran manual, sehingga pengukuran dibutuhkan waktu yang tidak sebentar agar nilai pengukuran lebih teliti. Kemudian untuk sistem pelaporan dan evaluasi perkembangan pertumbuhan balita itu sendiri masih dilakukan secara manual yaitu dengan mencatat setiap hasil pengukuran ke dalam Kartu Menuju Sehat (KMS) balita. Hal ini juga tentu saja membuat proses evaluasi menjadi tidak optimal karena proses evaluasi perkembangan bayi dilakukan secara manual yaitu dengan membandingkan antara hasil pengukuran dengan grafik perkembangan balita pada KMS. Dengan kondisi latar belakang tersebut tentu saja menjadi sebuah tantangan untuk bisa mengembangkan suatu sistem alat ukur tinggi badan elektronik untuk balita yang lebih optimal dan akurat dalam proses pengukurannya, serta sistem tersebut dapat mudah dibawa kemana-mana dan tanpa memerlukan koneksi internet untuk menghubungkan data hasil pengukuran ke gateway [10]. Hal ini dikarenakan tidak semua Posyandu memiliki koneksi internet Pembuatan alat ukur panjang badan telah dilakukan oleh beberapa peneliti, diantaranya Fajri mengembangkan alat ukur alat ukur tinggi dan massa tubuh bayi berbasis mikrokontroler atmega8535 dengan sensor fototransistor. Berdasarkan hasil penelitian dan analisis alat yang dirancang dapat mengukur tinggi badan dengan ketepatan sebesar 98,15\%. Spesifikasi alat yaitu tinggi minimum yang dapat diukur adalah $60 \mathrm{~cm}$. Kurang dari tinggi tersebut tidak dapat terdeteksi lagi oleh alat tersebut. Adanya persen kesalahan diakibatkan karena kurang tepatnya cahaya yang diterima oleh sensor fototransistor dari sumber cahaya pada alat panjang badan [5]. Pada penelitian lainnya telah juga digunakan transduser ultrasonik tipe HC-SR04 yang telah berhasil mengukur jarak objek $3-60 \mathrm{~cm}$ dengan error sebesar 0\% dan $60-200 \mathrm{~cm}$ dengan error sebesar 1,78\% [1]. Jenis transduser ultrasonik tipe lain seperti PING dan SRF04 telah juga digunakan untuk pengukuran panjang badan balita elektronik di Posyandu [6, 10]. Hal ini menunjukan bahwa transduser ultrasonik dapat digunakan untuk mengukur panjang balita yang panjangnya mulai dari $49-88 \mathrm{~cm}$.

Dari penelitian yang telah dilakukan terdapat kelebihan dan kekurangan yang bisa menjadi sebagai bahan referensi untuk dapat mengembang alat ukur massa tubuh dan panjang dengan lebih baik. Dalam kegiatan penelitian ini dilakukan perancangan dan realisasi sebuah box alat ukur panjang badan balita elektronik dengan berbasis PC berjenis Laptop PC. Cakupan penelitian yang dilakukan meliputi evaluasi nilai kepresisian, linearitas, dan akurasi dari pengukur panjang badan elektronik dengan menggunakan transduser ultrasonik dalam suatu box bayi khusus. Dengan adanya alat ukur panjang badan balita ini maka diharapkan proses evaluasi, pencatatan dan pemantauan perkembangan gizi balita akan diolah secara digital dan otomatis dengan komputer. Hal ini bertujuan agar dapat meningkatkan pelayanan kesehatan pada masyarakat dimana data hasil pengukuran dapat dievaluasi lebih cepat, serta data dapat disimpan dan dilaporkan secara berkala.

\section{MATERIAL DAN METODOLOGI PERANCANGAN}

Dalam melakukan perancangan dan realisasi box alat ukur panjang badan balita elektronik berbasis Laptop $P C$ dibagi dalam beberapa tahap mulai dari tahap perancangan sampai dengan tahap pengujian. Sistem ini terdiri dari tiga bagian yaitu perangkat keras mekanik, perangkat keras 
elektronik dan perangkat lunak. Diagram blok hubungan antara ketiga perangkat tersebut ditunjukkan pada Gambar 1. Perangkat keras mekanik yaitu berupa box alat ukur panjang badan untuk menempatkan balita yang akan diukur dalam posisi terlentang. Untuk perangkat keras elektronik terdiri dari alat ukur panjang badan, modul pemrosesan sinyal, display LCD, catu daya, modul komunikasi serial dan sebuah perangkat Laptop PC. Adapun perangkat lunak yang diimplementasikan pada sistem ini terdiri dari 2 perangkat lunak yaitu pada modul pemroses sinyal dan pada Laptop PC.

Adapun spesifikasi sistem box alat ukur panjang badan ini adalah range panjang badan yang diukur adalah $11 \mathrm{~cm}$ sampa dengan $103 \mathrm{~cm}$, objek diukur dalam kondisi terlentang, akuisisi besaran jarak menggunakan transduser ultrasonik, pemroses sinyal menggunakan Arduino UNO, display hasil pengukuran berupa LCD dan monitor Laptop PC, komunikasi data antara alat ukur dan PC menggunakan komunikasi serial, catu daya yang digunakan menggunakan adaptor dengan tegangan 5 VDC (1A) serta material box terbuat dari kayu dan harus mudah dibawa.

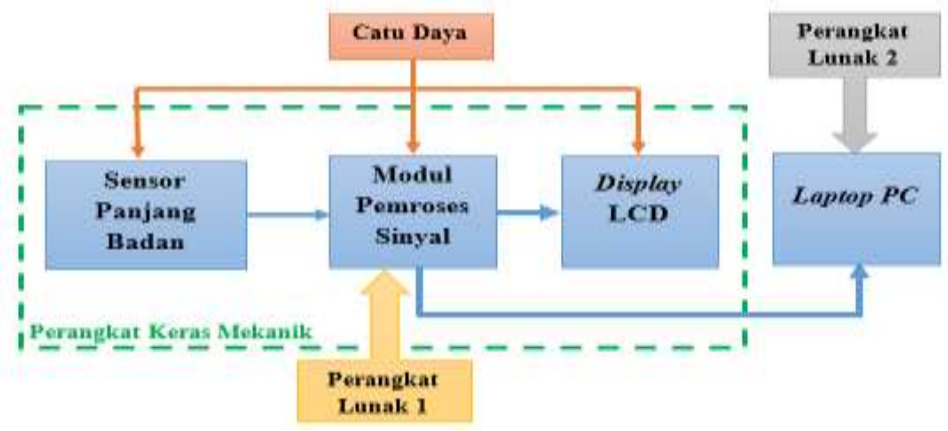

Gambar 1. Blok diagram sistem

\subsection{Perancangan Sistem Perangkat Keras Mekanik}

Pada perancangan sistem perangkat keras mekanik dilakukan desain dan realisasi alat ukur panjang badan untuk balita berupa box yang terbuat dari kayu untuk menempatkan balita dalam posisi terlentang. Ukuran box memiliki panjang $120 \mathrm{~cm}$ dan lebar $50 \mathrm{~cm}$. Ukuran box dipilih agar dapat mengukur balita dari lahir sampai dengan usia 2 tahun. Berdasarkan standar antropometri penilaian status gizi pada rentang usia tersebut, panjang balita akan berkisar mulai dari $40 \mathrm{~cm}$ sampai dengan $97 \mathrm{~cm}$ [1]. Pada pengukuran dalam box, alat mampu mengukur panjang balita mulai dari $11 \mathrm{~cm}$ sampai dengan $103 \mathrm{~cm}$. Dengan demikian, alat ini dapat digunakan untuk balita pada rentang usia tersebut. Gambar desain alat seperti yang terdapat pada Gambar 2.

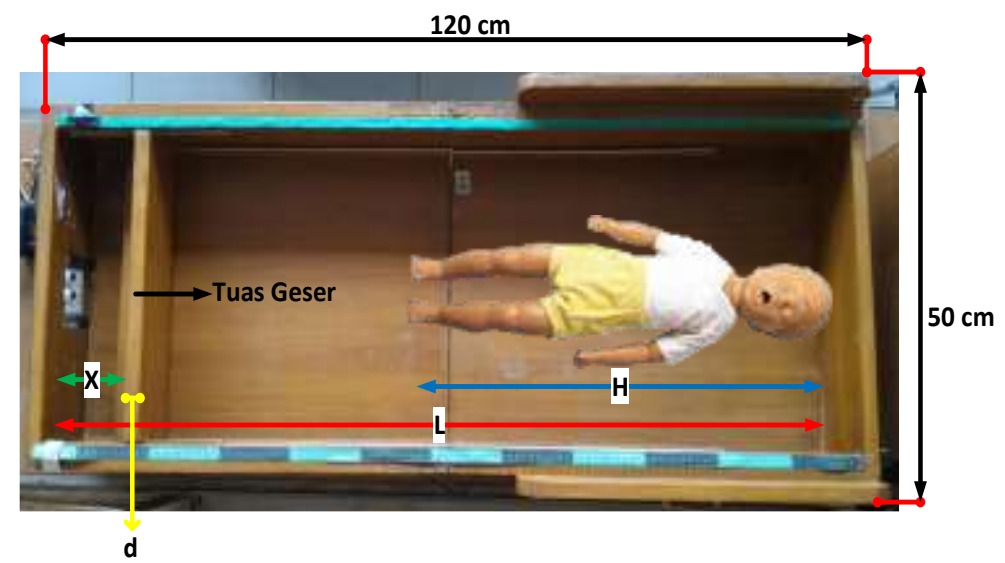

Gambar 2. Alat ukur panjang badan 
Box ini juga didesain dapat dilipat agar mudah untuk dibawa sehingga memungkinkan untuk digunakan di tempat yang berbeda. Prosedur pengukuran jarak atau tinggi pada box alat ukur ini adalah sebagai berikut: balita (objek) diletakkan dengan posisi telentang pada box dengan posisi kepala objek ditempatkan ke ujung box posisi atas dan pengukuran panjang objek terhadap box (X) akan dilakukan dengan bantuan tuas kayu geser yang akan diposisikan ke ujung kaki objek ketika diukur. Jarak objek terhadap box (X) merupakan jarak transduser yang diletakkan pada posisi bawah box terhadap kayu tuas geser (pada kaki objek) beserta dengan tebal kayu (d) yang digunakan. Hasil pengukuran jarak box terhadap objek diolah lebih lanjut pada modul pemroses sinyal.

\subsection{Perancangan Sistem Perangkat Keras Elektronik}

Perangkat keras elektronik yang dirancang pada sistem ini terdiri dari modul transduser berbasis ultrasonik sebagai sensor jarak, Arduino UNO digunakan sebagai pemroses sinyal, LCD 16x2 digunakan sebagai display hasil pengukuran, sebuah perangkat Laptop PC sebagai pengolahan dan penyimpan data hasil pengukuran serta catu daya berupa adaptor 5VDC dengan arus \pm 1 A. Cara kerja sistem perangkat keras elektronik ini dimulai dari pengukuran jarak objek dengan posisi terlentang terhadap box (X) menggunakan transduser ultrasonik. Selisih antara panjang box (L) dengan panjang objek terhadap box $(\mathrm{X})$ diolah menjadi tinggi badan objek $(\mathrm{H}=$ $\mathrm{L}-(\mathrm{X}+\mathrm{d})$ ) oleh modul Arduino UNO menggunakan parangkat lunak 1. Hasil pengolah data kemudian dikirimkan ke LCD untuk ditampilkan dan ke Laptop PC untuk diolah lebih lanjut guna melakukan evaluasi kondisi gizi balita. Selanjutnya data disimpan dalam Laptop PC. Komunikasi data antara modul Arduino UNO dengan Laptop PC menggunakan komunikasi data serial.

\subsection{Perancangan Sistem Perangkat Lunak}

Perancangan perangkat lunak meliputi perancangan program pada modul pemroses sinyal Arduino UNO dan perancangan program komunikasi data secara serial antara Arduino UNO dengan perangkat Laptop PC. Untuk komunikasi data antara Arduino UNO dengan program Microsoft Excel di Laptop PC menggunakan bentuan program PLX-DAQ melalui port USB. Secara lebih detail, perancangan setiap program dijelaskan melalui diagram alir pada Gambar 3.
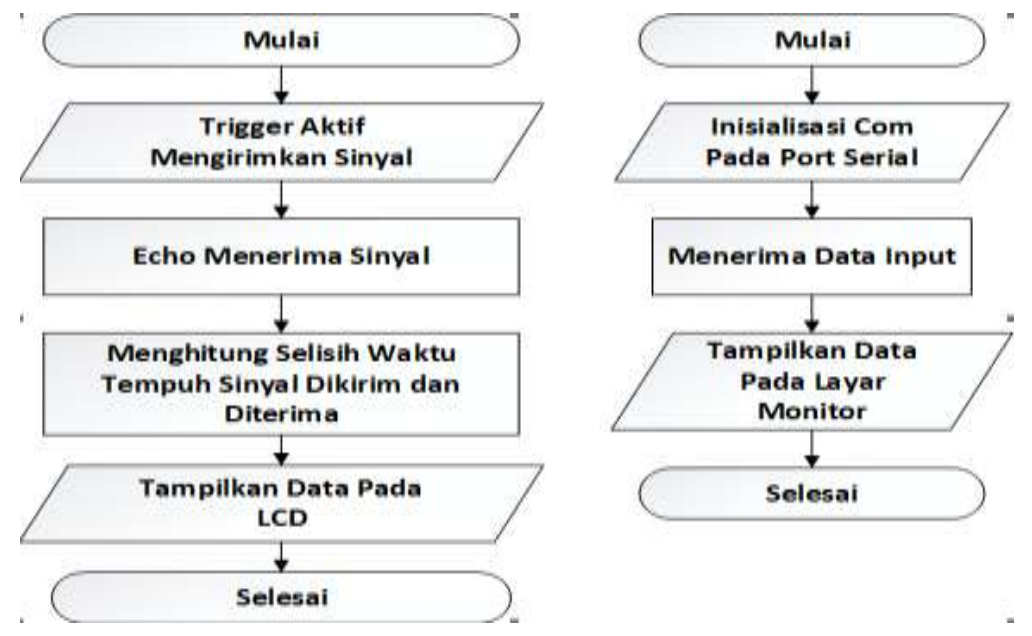

Gambar 3. (a) Flowchart sistem pada modul pemroses sinyal (b) flowchart sistem pada Laptop PC 


\subsection{Metodologi Pengujian}

Pada penelitian ini dilakukan dua jenis metodologi pengujian. Metodologi pengujian pertama meliputi pengujian kinerja alat ukur panjang badan untuk mengetahui tingkat linearitas, akurasi dan kepresisian. Pengujian pertama dilakukan dengan melakukan pengukuran menggunakan data panjang badan referensi balita usia $0-24$ bulan. Data referensi panjang badan balita didapatkan melalui buku standar antroprometri penilaian status gizi anak. Pengukuran dilakukan dengan data pada balita laki-laki dan perempuan, dimana nilai range panjang data balita laki-laki yaitu $50-88$ $\mathrm{cm}$ dan balita perempuan yaitu $49-87 \mathrm{~cm}$ [2]. Pengukuran dilakukan sebanyak tiga kali.

Metodologi pengujian yang kedua meliputi pengujian sistem komunikasi data secara serial untuk mengetahui tingkat akurasi sistem komunikasi data. Pengujian kedua dilakukan dengan melakukan perbandingan antara hasil tampilan pengukuran di serial monitor pada Laptop PC dengan tampilan di LCD, dimana dilihat apakah data yang diterima serial monitor sama dengan yang ada pada LCD. Pada pengujian ini menggunakan skema pengukuran pada pengujian yang pertama. Pengujian dilakukan sebanyak tiga kali.

\section{HASIL PENGUJIAN DAN ANALISIS}

\subsection{Pengujian Pertama}

Dari pengujian pertama didapat dua hasil pengujian berdasarkan referensi panjang balita laki-laki dan juga perempuan, hasil tersebut kemudian diolah untuk mendapatkan nilai linieritas, akurasi dan kepresisian. Hasil pengujian nilai linieritas dan akurasi ditunjukkan pada Gambar 4(a) dan Gambar 4(b). Nilai lineritas total rata-rata panjang hasil pengukuran dan panjang referensi untuk usia balita laki-laki adalah $\mathrm{R}^{2}=0,9458$ dan untuk balita perempuan adalah $\mathrm{R}^{2}=0,9623 \mathrm{Jika}$ dilihat nilai linearitas $\mathrm{R}^{2}$ maka dapat dinyatakan bahwa hasil pengukuran relatif linier.

Akan tetapi, pada garis total rata-rata panjang dengan panjang referensi terdapat celah yang dimana seharusnya kedua garis tersebut saling berhimpitan. Celah yang terlihat pada grafik menunjukan adanya nilai error. Nilai rata-rata error mencapai angka $5 \mathrm{~cm}$ atau $6,91 \%-7,05 \%$ (terhadap nilai referensi panjang badan balita laki-laki dan perempuan) dimana seharusnya nilai error adalah nol atau paling tidak $1 \mathrm{~cm}$ sesuai dengan spesfikasi ketelitian alat yang diinginkan. Hal itu disebabkan oleh beberapa faktor seperti transduser ultrasonik kurang maksimal pada saat digunakan di dalam sebuah box alat ukur panjang badan. Padahal jika dilihat pada banyak penelitian sebelumnya telah membuktikan bahwa alat ukur tinggi badan berbasis transduser ultrasonik sangat baik dan mampu mengukur sampai sejauh $200 \mathrm{~cm} \mathrm{[4].} \mathrm{Akan} \mathrm{tetapi,} \mathrm{hal} \mathrm{tersebut}$ memang terjadi apabila transduser digunakan pada kondisi di luar box (tanpa penghalang di samping kiri dan kanan transduser). Pada kondisi di dalam box, papan yang berada di samping kiri dan kanan mempengaruhi transduser sehingga tidak dapat bekerja dengan baik. Hal ini disebabkan karena sinyal yang dikirimkan tranduser akan memantul pada pinggiran box sebelum mencapai objek yang dituju. Melihat kondisi seperti itu maka perlu dilakukan upaya untuk memperbaiki alat ukur dengan melepas papan pada box yang berada di pinggir agar dapat memperbaiki kinerja transduser ultrasonik 


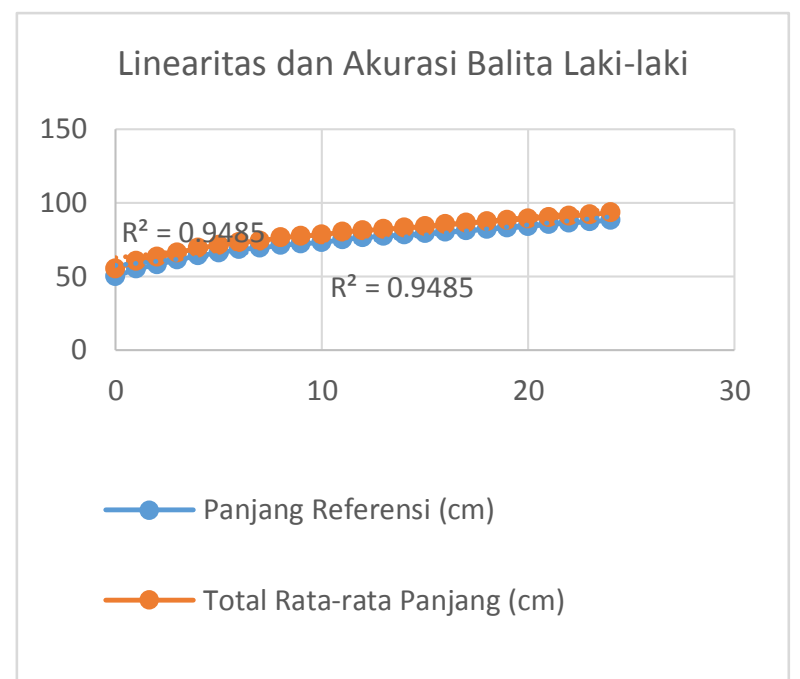

(a)

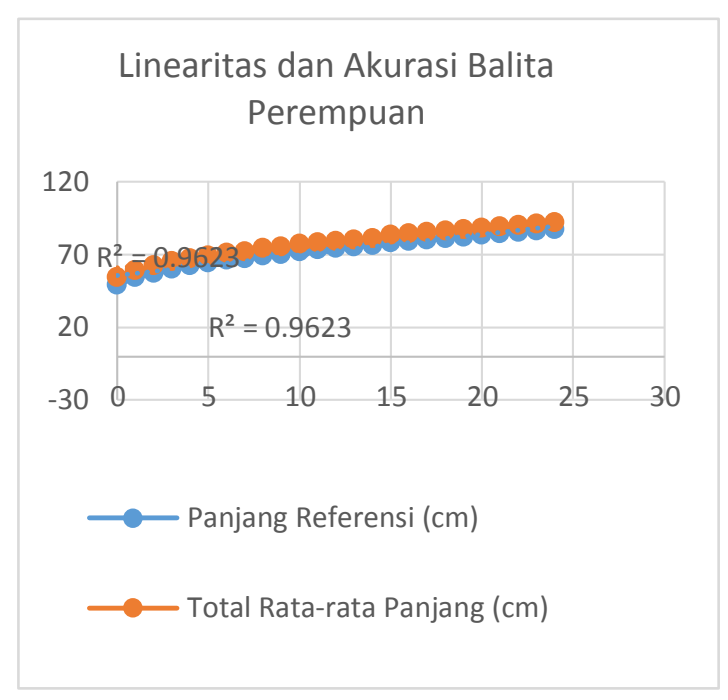

(b)

Gambar 4. (a) Grafik linearitas dan akurasi balita laki-laki (b) Grafik linearitas dan akurasi balita perempuan

Untuk nilai presisi didapat dari data hasil pengukuran yang dilakukan sebanyak tiga kali seperti ditunjukkan pada Gambar 5(a) dan Gambar 5(b). Dari nilai pengukuran tiga kali tersebut, kemudian setiap data yang didapat pada pengukuran dikurangkan dengan rata-rata nilai panjang pengukuran, maka didapat nilai presisi setiap percobaan. Nilai kepresisian alat ukur panjang badan yang didapatkan dari pengukuran panjang terhadap data referensi balita laki-laki maupun perempuan dihasilkan nilai kepreisisian yang sangat baik yaitu sama dengan 0 (nol). Hal ini ditunjukkan dengan garis grafik pengukuran 1, pengukuran 2, pengukuran 3 dan nilai rata-rata pengukuran saling berhimpitan satu sama lain tanpa adanya celah sedikit pun.

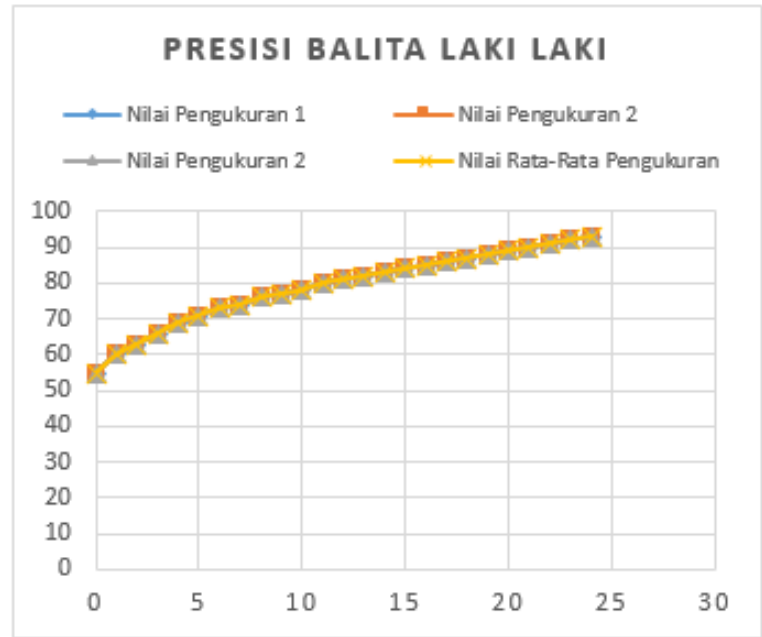

(a)

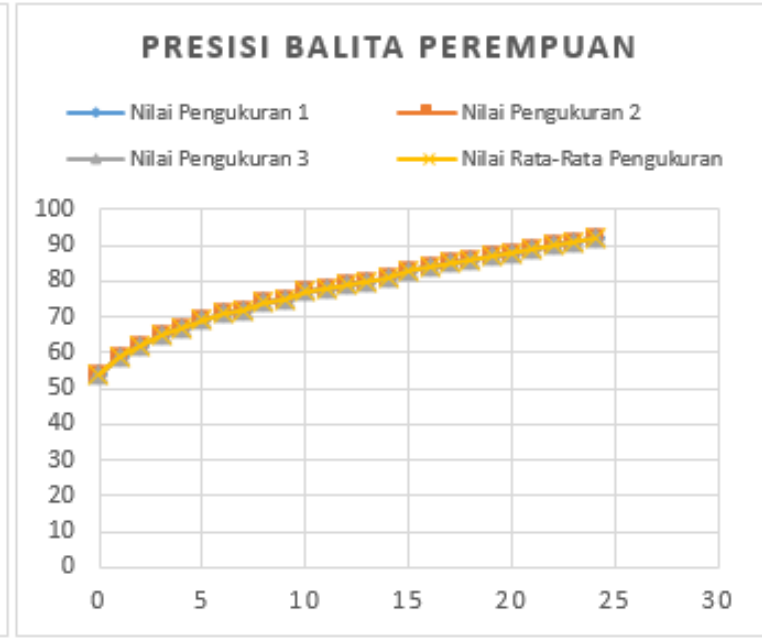

(b)

Gambar 5. (a) Grafik presisi balita Laki-laki (b) Grafik presisi balita perempuan

\subsection{Pengujian Kedua}

Percobaan yang kedua dilakukan pengujian sistem komunikasi data secara serial untuk mengetahui tingkat akurasi sistem komunikasi data guna melihat apakah sistem komunikasi data secara serial berjalan baik tanpa adanya kegagalan. Dari prosedur ini didapatkan hasil pengujian 
alat ukur panjang badan digital untuk balita seperti ditunjukkan pada Gambar 6(a) dan Gambar 6(b).

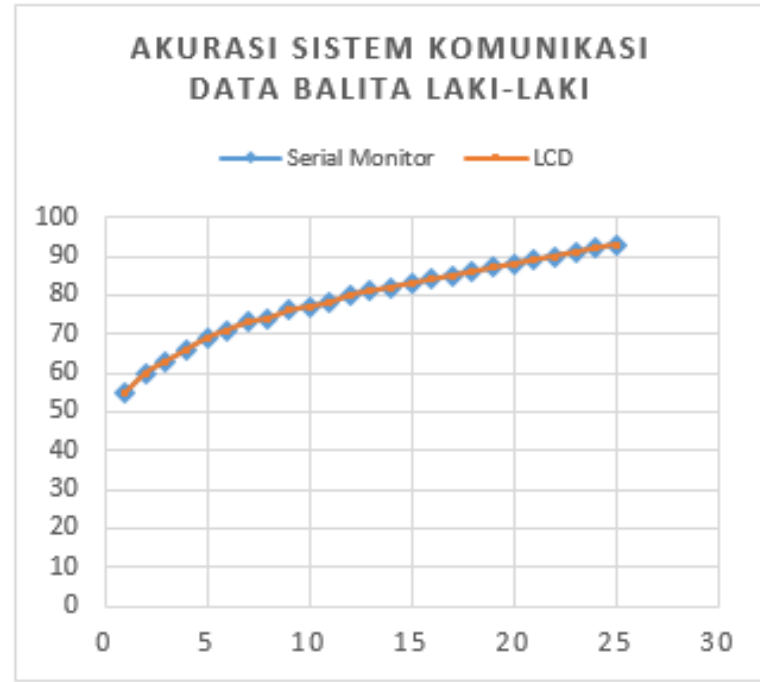

(a)

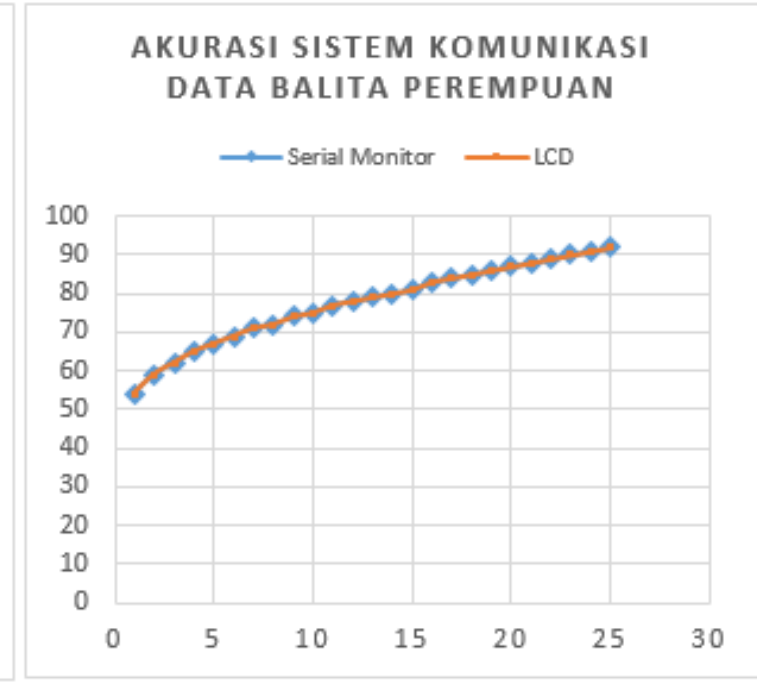

(b)

Gambar 6. (a) Grafik akurasi sistem komunikasi data balita laki-laki (b) Grafik akurasi sistem komunikasi data balita perempuan

Pada grafik hasil pengujian dapat dilihat bahwa garis grafik serial monitor dan LCD saling berhimpitan tanpa adanya celah sedikit pun. Hal ini membuktikan bahwa hasil data yang muncul pada serial monitor sama dengan data pada LCD. Dengan begitu terlihat bahwa tingkat akurasi sistem komunikasi data secara serial sangat baik, tanpa adanya kegagalan koneksi atau kecacatan data yang muncul.

\subsection{Perbaikan Sistem}

Perbaikan sistem dilakukan untuk dapat mengatasi nilai error pada hasil pengukuran. Dikarenakan perbaikan sistem tidak dapat dilakukan dengan mengubah konstruksi box, maka perbaikan sistem dilakukan dengan cara melakukan kalibrasi hasil pengukuran yang dikurangkan dengan nilai error. Kalibrasi dilakukan dengan cara memasukan nilai error $(5 \mathrm{~cm})$ pada persamaan yang ada pada program Arduino. Kemudian dilakukan pengujian ulang satu kali dengan menggunakan data panjang referensi balita laki laki dan perempuan. Didapatkanlah hasil pengujian alat ukur panjang badan digital untuk balita seperti ditunjukkan pada Gambar 7(a) dan 7(b). Dilihat dari grafik diketahui bahwa pada pengujian kalibrasi sistem ini didapatkan nilai error nol, dimana sudah tidak terdapat lagi celah antara garis referensi dengan hasil pengukuran. Hal ini menunjukkan bahwa sistem kalibrasi ini dapat memperbaiki sistem alat ukur panjang badan dengan baik. 


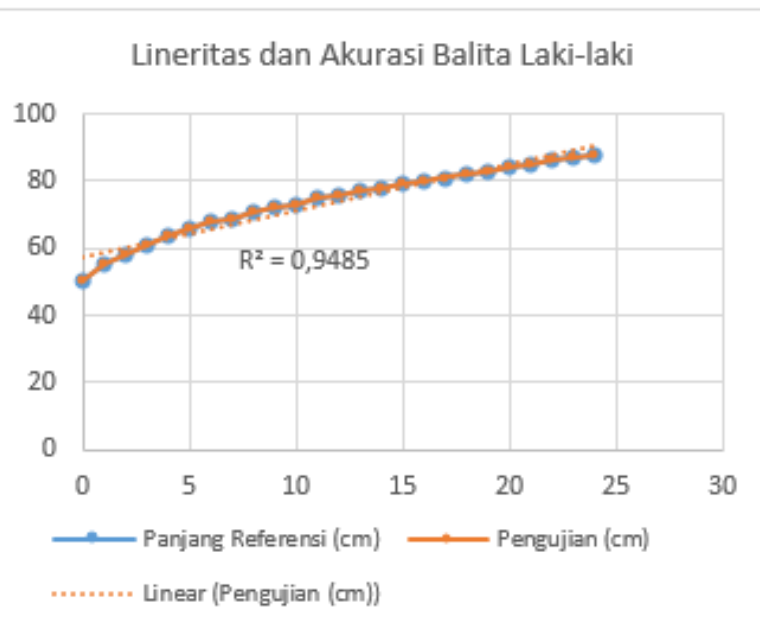

(a)

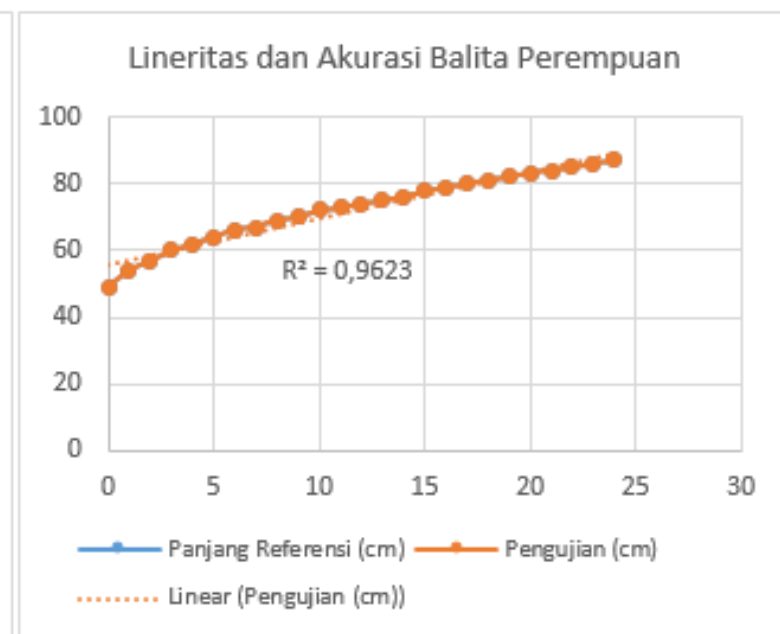

(b)

Gambar 7. (a) Grafik linearitas dan akurasi balita laki-laki (b) Grafik linearitas dan akurasi balita perempuan

\section{KESIMPULAN}

Dari hasil penelitian ini bisa ditarik sejumlah kesimpulan yaitu:

1. Nilai linieritas dapat dicapai sebesar $R^{2}=0,9458$ pada data balita laki-laki dan $R^{2}=0,9623$ pada data balita perempuan.

2. Nilai kepresisian diperoleh sama dengan nol.

3. Setelah dilakukan perbaikan sistem, tingkat akurasi alat ukur panjang badan diperoleh nilai error sebesar $0 \mathrm{~cm}$ atau $0 \%$.

4. Sistem komunikasi data pada alat ini memiliki nilai tingkat akurasi yang baik, dimana pada saat data muncul pada serial monitor sama persis dengan data yang muncul pada LCD. Artinya sistem komunikasi data antara alat ukur dengan Laptop PC dapat berjalan dengan baik yaitu data diterima secara utuh tanpa adanya kecacatan data.

\section{DAFTAR PUSTAKA}

[1] Arsada B, dan Suprianto B. 2017. Aplikasi Sensor Ultrasonik Untuk Deteksi Posisi Jarak Pada Ruang Menggunakan Arduino Uno. Jurnal Teknik Elektro. 6:2 137 - 145

[2] Departemen Kesehatan. 2011. Standar Antropometri Penilaian Status Gizi Anak. Jakarta: Kementrian Kesehatan Republik Indonesia.

[3] Departemen Kesehatan. 2013. Gizi Seimbang Atasi Masalah Gizi Ganda. [Online] Tersedia dihttp://www.depkes.go.id/article/view/2239/gizi-seimbang-atasi-masalah-giziganda.html\#sthash.oYY78gId.dpuf [diakses 2 Maret 2016].

[4] Dini, W. S. 2014. Pengukur Tinggi Badan Digital Menggunakan Sensor Ultrasonik HCSR04 Berbasis Arduino Uno. Jakarta: Universitas Gunadarma.

[5] Fajri N. 2014. Rancang Bangun Alat Ukur Alat Ukur Tinggi Dan Massa tubuh Bayi Berbasis Mikrokontroler Atmega8535 Dengan Sensor Fototransistor. Jurnal Fisika Unand. 3:3 163169

[6] Kusumah H, Toro A, dan Idris M. 2015. Sistem Pengukur Tinggi Dan Massa tubuh Untuk Posyandu Menggunakan Mikrokontroler Atmega8535. CCIT Journal. 9:2 168-178

[7] Purnama, A. 2012. Liquid Cristal Display. [Online] Tersedia di http://elektronikadasar.web.id/lcd-liquid-cristal-display/ [diakses 11 Agustus 2016] 
[8] Sakti, E. 2015. Sensor Ultrasonik. [Online] Tersedia di http://www.elangsakti.com/2015/05/sensor-ultrasonik.html [diakses 2 Maret 2016]

[9] Taufik, A. 2014. Arduino Uno. [Online] Tersedia di http://dialogsimponi.blogspot.co.id/2014/11/normal-0-false-false-false-in-x-none-x.html [diakses 22 Juli 2016].

[10] Wardana B P. 2011. Rancang Bangun Sistem Deteksi Gizi Buruk Pada Balita Usia Dini Di Posyandu Berdasar Berat Badan Dan Tinggi Badan Yang Terhubung Dengan PC Berbasis Internet Gateway. EEPIS. Politeknik Elektronika Negeri Surabaya. 